\title{
Entre as "máfias" e a "ajuda": a construção de conhecimento sobre tráfico de pessoas*
}

\author{
Adriana Piscitelli*
}

\begin{abstract}
Resumo
Neste artigo comento algumas dificuldades relativas à produção do conhecimento sobre tráfico de pessoas. Tomo como referência experiências de pesquisa realizadas no Brasil e na Espanha que mostram a importância de mapear e situar os pressupostos dos diferentes grupos de interesse envolvidos, incluindo as pessoas que se espera proteger $e$ atender. Analiso problemas metodológicos, discutindo os efeitos da vigência de diferentes definições de tráfico de pessoas na produção de dados $e$ documentos. Finalmente, levo em conta a contribuição das distinções entre crime e violação dos direitos humanos para refletir sobre um dos aspectos presentes no material: a distância entre a percepção de pessoas tecnicamente consideradas vítimas de tráfico e definições legais desse crime.
\end{abstract}

Palavras-chave: Tráfico de Pessoas, Crime, Direitos Humanos, Gênero, Prostituição.

\footnotetext{
" Recebido para publicação setembro de 2008, aceito em outubro de 2008.

*** Pesquisadora do Núcleo de Estudos de Gênero - Pagu, Universidade Estadual de Campinas.pisci@uol.com.br
} 
Entre as "máfias" e a "ajuda"

Between the "Mafias" and "Help":

The Building of Knowledge on Human Trafficking

\begin{abstract}
In this article, I comment on some difficulties related to the building up of knowledge on human trafficking. I base myself on research experience carried out in Brazil and in Spain which shows the importance of mapping and locating the notions of the different interest groups involved, including those people whom it is expected to protect and help. I analyze methodological problems, discussing the effects of the validity of the different definitions of human trafficking in the production of data and documents. In conclusion, I take into consideration the distinctions between crime and the violation of human rights so as to reflect on one of the aspects present in the material: the distance between the perception of those technically considered to be victims of trafficking and the legal definitions of this crime.
\end{abstract}

Key Words: Human Trafficking, Crime, Human Rights, Gender, Prostitution 
Neste texto realizo alguns comentários a respeito dos problemas enfrentados na produção de conhecimento sobre tráfico de pessoas, um dos aspectos questionados no debate crítico sobre o tema. Nessa discussão, diversas leituras problematizam aspectos das formulações do Protocolo de Palermo relativo ao tráfico de pessoas e de sua implementação. ${ }^{1}$

Um dos pontos levantados é que esse instrumento legal concede particular importância à proteção dos direitos fundamentais das vítimas, mas sua implementação acarreta diversos efeitos negativos para as pessoas a serem protegidas. ${ }^{2}$ Essas conseqüências são vinculadas ao entrecruzamento de interesses, não necessariamente coincidentes, de governos $e$ entidades de apoio aos direitos humanos na formulação desse Protocolo e em sua aplicação (Kempadoo 2005 e 2005b; Anderson e O'Connell Davidson, 2004; Doezema 2005; Piscitelli, 2006).

Em várias partes do mundo, pesquisadores, organizações não governamentais e coletivos de prostitutas registram esses efeitos, sintetizados na expressão collateral damage. Eles envolvem aspectos diversificados. Um deles é a restrição de movimento dos jovens, em países africanos, impedindo que deixem suas aldeias para evitar que sejam traficados. Outro, a internação forçada de prostitutas estrangeiras (mesmo que afirmem não terem sido traficadas) em abrigos custodiados pela polícia, durante meses, na Europa Oriental. O terceiro aspecto é a recorrente detenção em operações contra o tráfico de pessoas em países da Europa Ocidental, principalmente de mulheres trabalhando na indústria do sexo, que, no lugar de aceder à proteção a ser concedida às vítimas desse crime, são

1 Este texto está vinculado a pesquisas apoiadas pela FAPESP (Projeto Temático Gênero e Corporalidades), pelo CNPq e pela CAPES.

2 Para uma análise do conteúdo do Protocolo de Palermo, suas diferenças em relação a formulações legais anteriores sobre o tráfico de pessoas e o particular lugar que concede à proteção dos direitos humanos, ver apresentação deste dossiê. 
Entre as "máfias" e a "ajuda"

aprisionados/as e deportados/as por serem migrantes não documentados (GAATW, 2007; Adams, 2003; Piscitelli, 2007).

Outro questionamento refere-se ao intenso crescimento de um setor social voltado para o resgate de prostitutas migrantes (não apenas daquelas em situação de tráfico) (Agustín, 2007). Kamala Kempadoo (2005) chama a atenção para o escasso consenso existente entre pesquisadores, formuladores de políticas $e$ ativistas sobre a dimensão desse aspecto específico do tráfico de pessoas. Entretanto, essa "indústria do resgate" não cessa de aumentar.

No conjunto de críticas, um dos pontos mais destacados se refere à confusão conceitual presente no âmbito do debate e das ações voltadas para o combate ao tráfico de pessoas, incluindo a produção de conhecimento sobre o tema. Isso se deve a que nesse campo, como assinala Kempadoo (2005), há diferentes (e conflitantes) definições de tráfico de pessoas.

Em finais da década de 1990, no cenário da efervescência suscitada pelas novas discussões feministas em torno do tráfico de mulheres $^{3}$, Alison Murray (1998) problematizava os dados apresentados em relatórios produzidos sobre o tema na Ásia, região privilegiada no ressurgimento do debate. De acordo com a autora, esses documentos apresentavam três fragilidades básicas: as definições de tráfico que guiavam as pesquisas eram imprecisas, as cifras e estatísticas não eram explicadas nem

${ }^{3}$ A autora situa o ressurgimento do interesse no tráfico de mulheres, diluído após a formulação da Convenção das Nações Unidas de 1949, no final da década de 1980, vinculado, sobretudo, à preocupação pela relação entre tráfico $e$ turismo sexual. Essas inquietações deram lugar a várias conferências importantes na primeira metade da década de 1990: - a Conferência organizada pela coalizão abolicionista Coalition against the trafficking of Women (CATW), em 1993; - a Primeira Conferência Internacional sobre Tráfico de Mulheres em Chiang Mai, Tailândia, em 1994, na qual se organizou outra grande coalizão feminista que, diferentemente da anterior, opera com perspectivas afinadas com os interesses das trabalhadoras do sexo, a Global Alliance Against Trafficking in Women, GAATW; - a Conferência Internacional sobre Tráfico de Pessoas, em Utrecht em 1994 (Murray, 1998). 
referenciadas e se realizavam generalizações a partir da base de dados relativa a amostras altamente seletivas de prostitutas. Apesar desses problemas, o interesse de situar o tráfico de pessoas na agenda política global fez com que a informação disseminada nesses relatórios, amplificada pela mídia, alcançasse rapidamente o estatuto de verdade (Murray, 1998).

Dez anos depois, no âmbito da intensificação do debate após a formulação do Protocolo de Palermo, questionamentos análogos se difundiram em diversas partes do mundo, inclusive no Brasil. (Kempadoo, 2005; Grupo Davida, 2005). Ao mesmo tempo, no país, registros de diversas entidades apresentam casos de deslocamentos de pessoas para serem submetidas a trabalho forçado ou escravo em diferentes setores de atividade, mantidas em cárcere privado, sujeitas à violência física e/ou ameaças (Sódireitos/GAATW, REDLAC, 2008; ASBRAD, 2008; Costa, nv; Illes et alii, nv). Esse quadro envolve uma problemática altamente politizada, regulações supranacionais e nacionais e questões de direitos humanos e coloca diversos problemas que suscitam dúvidas entre os/as pesquisadores/as sobre como abordar $e$ analisar a problemática. ${ }^{4}$

Compartilhando essas inquietações, neste artigo comento algumas dificuldades relativas à produção do conhecimento sobre o tema, tomando como referência experiências de pesquisas sobre tráfico internacional de pessoas e sobre migrações vinculadas à indústria do sexo. Os problemas enfrentados nesses trabalhos apontam para a crucial importância de mapear e situar os pressupostos dos diferentes grupos de interesse envolvidos na

\footnotetext{
${ }^{4}$ Várias das idéias deste texto foram discutidas em encontros e seminários. Agradeço os comentários dos participantes da mesa redonda "O Mundo do trabalho pelo avesso: as práticas de trabalho escravo, infantil e no tráfico de drogas", ANPOCS, 2007 e, em 2008, Workshop pré-ABA: Regulações Internacionais, direitos diferenciados e políticas de reconhecimento; Simpósio Especial "Gênero no Tráfico de Pessoas e Migrantes", 26ª Reunião da ABA; Seminário "Gênero no Tráfico de pessoas", Unicamp, e "III Seminário do Núcleo Interdisciplinar de Estudos Migratórios".
} 
Entre as "máfias" e a "ajuda"

problemática, incluindo as pessoas que se espera proteger $e$ atender. Esse exercício requer levar em conta que se trata de uma arena permeada pelo entrecruzamento de planos supranacionais, transnacionais e nacionais (Rapport e Overing, 2000). ${ }^{5}$ Tal leitura, além de contribuir para compreender as noções de direito em jogo e como elas são criadas e transformadas, fornece um contexto para entender os problemas metodológicos enfrentados pelos estudiosos do tema.

Faço esses comentários considerando tensões e articulações entre diferentes lógicas normativas que permeiam a implementação do Protocolo de Palermo. Em seguida, discuto os efeitos da vigência de diferentes definições de tráfico na produção de dados e documentos. Finalmente, levo em conta a contribuição das distinções entre crime $e$ violação dos direitos humanos para refletir sobre um dos aspectos presentes no material sobre tráfico de pessoas: a distância entre a percepção das pessoas tecnicamente consideradas vítimas de tráfico e as definições legais desse crime.

\section{Desencontros e articulações}

A formulação, harmonização e implementação de normativas legais relativas ao tráfico de pessoas têm lugar no cenário de embates políticos, nos quais há desencontros $e$ articulações entre as lógicas normativas que orientam ações de diferentes grupos de interesse. Desencontros e convergências são perceptíveis no entrecruzamento entre lógicas dos estados nacionais e outras que podem ser consideradas supranacionais $e$ transnacionais. E, muitas vezes, há desencontros entre essas lógicas $e$ as que permeiam as ações de pessoas consideradas em situação de tráfico.

O tráfico de pessoas é considerado um problema crucial por governos e por entidades que defendem os direitos humanos,

${ }^{5}$ Para as distinções entre esses termos, ver nota 1 na apresentação deste dossiê. 
incluindo organizações feministas e grupos de apoio às pessoas que trabalham na indústria do sexo (Anderson e O'Connell Davidson, 2004). Os interesses desses grupos conduzem a interpretações e agendas políticas diferenciadas. De acordo com as leituras críticas sobre o tema, nessas instâncias, a questão é tratada basicamente como problema moral, de crime organizado ou de migração (Ausserer, 2007; Weitzer, 2007). Vale lembrar que as acirradas discussões internacionais sobre o tráfico de pessoas têm lugar em contextos marcados pela obsessão com os migrantes não documentados.

No debate, tem-se concedido particular importância às abordagens feministas sobre o tema, porque elas tiveram um peso significativo na organização de lobbies durante a elaboração do Protocolo. Essas perspectivas convergem no interesse em promover o bem-estar das mulheres, mas se dividem no que se refere à concepção da prostituição e da relação entre prostituição $e$ tráfico de pessoas. Nessa separação, elas expressam visões divergentes sobre a relação entre gênero e sexualidade, elaboradas no intenso debate anglo-saxão sobre o tema, as guerras do sexo (sex wars), a partir da década de 1980 (Cornell, 2000; Chapkis, 1997). Por esse motivo, as feministas participaram das negociações, organizando-se em dois campos com pontos de vista diferentes, às vezes opostos.

De acordo com as análises de participantes no processo de elaboração do Protocolo, um desses campos, organizado em torno da CATW/Coalition Against the Trafficking in Women, deu voz às abordagens "abolicionistas" (Doezema, 1998). Essas perspectivas afirmam que a prostituição reduz as mulheres a objetos comercializáveis, portanto, é sempre e necessariamente degradante e danosa para as mulheres. Essas posições não reconhecem uma distinção entre prostituição forçada e por livre escolha e sustentam que, tolerando, regulando ou legalizando a prostituição, os Estados permitem a violação dos direitos humanos. Assim, as medidas para erradicar a indústria do sexo 
Entre as "máfias" e a "ajuda"

são consideradas como ações contra o tráfico e vice-versa (Barry, 1997).

Outras abordagens feministas se alinharam com as entidades que apóiam os direitos das/os trabalhadoras/es sexuais. Essas perspectivas rejeitam a idéia de que a prostituição é inerentemente degradante e, considerá-la como uma forma de serviços, de trabalho, traçam nítidas distinções entre a prostituição voluntária exercida por adultos, a prostituição forçada $e$ a prostituição infantil. A idéia central é que o tráfico de pessoas não se vincula de maneira automática à indústria do sexo, mas essa relação é favorecida pela falta de proteção dos/as trabalhadores/as nesse setor de atividade. Nessas perspectivas, considera-se que quem trafica se beneficia da ilegalidade da migração e do trabalho sexual. Essa dupla ilegalidade é a fonte do poder e controle que exercem sobre os/as migrantes. Nesses casos, as leis que impossibilitam a migração e o trabalho sexual legais constituem os principais obstáculos para os/as migrantes que se inserem na indústria do sexo no exterior. Essas abordagens, organizadas em torno do Human Rights Caucus, defenderam veementemente que força e engano eram centrais para a definição de tráfico.

Sem negar a importância dessa oposição na formulação de algumas partes do Protocolo de Palermo, responsabilizar as perspectivas feministas pelos rumos seguidos no combate ao tráfico de pessoas seria simplista. Compreender esses caminhos requer pensar como outros grupos se alinharam com essas abordagens e utilizaram aspectos de argumentos feministas em função de outros interesses.

Diversos autores assinalam que, em termos dos governos, as definições de tráfico de pessoas estão associadas ao controle e prevenção do crime organizado transnacional e à preocupação com violações das leis de imigração (Anderson e O'Connell Davidson, 2004; Kempadoo, 2005). Caroline Ausserer (2007) observa que na maioria dos países há uma ênfase na resposta da justiça criminal para combater o tráfico, que é atribuído a grupos de crime organizado. Os interesses dos sujeitos em situações de 
tráfico são subordinados aos interesses do Estado, materializados na repressão ao crime. Entretanto, essa ênfase tende a estar entrelaçada com a relevância concedida pelos governos ao combate à migração não documentada. A associação do tráfico de pessoas a formas de migração não documentada conduz à sua conexão com a ilegalidade e a criminalidade, reforçando a imagem do tráfico como ameaça à segurança nacional. $\mathrm{E}$ a deportação das pessoas, afetadas pelo tráfico e políticas de migração mais estritas, são consideradas soluções para o problema (Ausserer, 2007).

Levar em conta esses interesses é relevante para compreender a participação dos governos e a pressão de lobbies transnacionais, como as coalizões feministas na formulação do Protocolo de Palermo relativo ao tráfico de pessoas. Todavia, não é possivel realizar generalizações sobre os interesses particulares de diferentes países do Norte e do Sul que ratificaram esse instrumento legal supranacional ${ }^{6}$, nem sobre as maneiras em que foi implementado. Tampouco é adequado fazer generalizações sobre como as "guerras do sexo" transmigraram e foram atualizadas em diferentes partes do mundo.

\section{Relações}

O governo brasileiro ratificou o Protocolo de Palermo, em 2004, em um cenário no qual a renovação do movimento contra o tráfico de pessoas já era intensa. Essa história está começando a ser alvo de pesquisas (Oliveira, 2008; Skackauskas, 2007). Contudo, os documentos disponíveis e vários dos seminários e encontros,

\footnotetext{
${ }^{6}$ Nesse ponto, vale lembrar a observação de Kamala Kempadoo (2005) relativa a que os parâmetros vigentes para a avaliação anual dos esforços de diferentes países para combater o tráfico, sujeitando a sanções àqueles situados no nível mais baixo, seguem critérios estabelecidos pelo Departamento de Estado do Estados Unidos. Para uma idéia desses critérios ver: Trafficking in Persons Interim Assessment, 2007 (http://www.state.gov/g/tip/rls/rpt/78948.htm consultado em 8/09/2008).
} 
Entre as "máfias" e a "ajuda"

organizados por instâncias governamentais e/ou agências multilaterais, indicam que essa discussão apresenta algumas particularidades.

Um desses aspectos se refere à participação dos movimentos sociais na re-ativação do debate. Enquanto no mundo anglosaxão as feministas se debatiam nas "guerras do sexo" em torno da pornografia e prostituição, a organização dos grupos feministas brasileiros girou em torno de outras questões. O feminismo se desenvolveu, a partir da década de 1970, em um contexto marcado pelas desigualdades e pelo peso da ditadura militar. Esse cenário mantém relações com as preocupações do movimento (Moraes, 1996), que privilegiou a luta contra a ditadura e a violência contra as mulheres (Corrêa, 1984) e, posteriormente, questões relacionadas com a saúde da mulher $e$ os direitos reprodutivos. (Sarti, 2004). De acordo com depoimentos de diversas ativistas, durante as décadas de 1970 e 1980, a prostituição não integrou esse leque de inquietações. ${ }^{7}$

No final da década de 1990, no âmbito de articulações feministas transnacionais, a crescente preocupação com as relações estabelecidas entre turismo sexual e tráfico internacional de pessoas era perceptível nas ações de algumas organizações não governamentais voltadas para as mulheres. Trata-se de entidades que trabalham em cidades do Nordeste tidas como alvo do turismo sexual (Coletivo mulher vida, 1996; Chame, 1998). Contudo, em termos da sociedade civil organizada, na virada do milênio, a articulação contra $\mathrm{o}$ tráfico de pessoas esteve associada, sobretudo, à pressão dos movimentos pelos direitos da criança.

Em 2000 teve início a Pesquisa nacional sobre o tráfico de mulheres, crianças e adolescentes para fins de exploração sexual comercial (PESTRAF), apoiada por fundos internacionais $e$ considerada um marco nas articulações contra o tráfico de pessoas no Brasil. A coordenação nacional e a articulação institucional

7 Comunicações pessoais de Albertina Costa, Sônia Corrêa e Mariza Corrêa, em 2007. 
governamental estiveram vinculadas a instâncias de defesa dos direitos de crianças e adolescentes. A pesquisa - alvo de diversas críticas em função de problemas metodológicos - foi difundida nacionalmente em 2002 com o propósito político de chamar a atenção do debate público sobre o tema.

Um segundo aspecto que caracteriza o debate sobre tráfico de pessoas no Brasil é a importância assumida pelo apoio das agências multilaterais supranacionais ao governo $e$ à organizações não governamentais. Em 2001, a Secretaria Nacional de Justiça e o Escritório das Nações Unidas contra as Drogas e Crimes (UNODC) assinaram um acordo de cooperação técnica para o enfrentamento ao tráfico de pessoas, em especial de mulheres para fins de exploração sexual. $\mathrm{O}$ projeto envolvia ações em quatro Estados brasileiros - Goiás, Ceará, Rio de Janeiro e São Paulo. ${ }^{8}$ A proposta era realizar diagnósticos, na forma de pesquisas, ações de capacitação centradas nos operadores de Direito e outros funcionários públicos da rede de atenção à vítima, campanhas de conscientização da população e a formação de um banco de dados nacional sobre o tema (Secretaria Nacional de Justiça, 2007).

Em 2004, no âmbito do programa da Secretaria Nacional de Justiça, foram criados quatro escritórios de Combate e Prevenção ao Tráfico de Seres Humanos em São Paulo, Rio de Janeiro, Goiânia e Fortaleza. A idéia era articular os escritórios com a polícia e com redes de serviços para o atendimento das vítimas de tráfico. Foram realizadas pesquisas e seminários, com apoio do governo, do UNODC e também da Organização Internacional do Trabalho (OIT), em diversas partes do país e cursos de capacitação e sensibilização para operadores de direito, policiais, agentes que trabalham em aeroportos, e pessoas de instâncias governamentais $e$ não governamentais que trabalhariam no atendimento às

\footnotetext{
8 Os dois primeiros, por serem considerados locais de origem de parte significativa das vítimas, $e$ os outros dois, por contarem com os principais aeroportos internacionais do país.
} 
Entre as "máfias" e a "ajuda"

vítimas. Entre 2005 e 2006 foi elaborada a Política Nacional de Enfrentamento ao Tráfico de Pessoas, que incluiu uma ampla consulta à sociedade (Ministério da Justiça, 2007).

Neste processo, a articulação entre movimentos de apoio aos direitos humanos, governo, agências multilaterais supranacionais e redes feministas transnacionais teve efeitos no movimento feminista brasileiro. O programa do X Encontro Feminista Latinoamericano e do Caribe, realizado em São Paulo, em 2005, incluiu dois painéis, preparados por ativistas brasileiras, sobre a problemática. Hoje, o tráfico de pessoas é um dos principais temas de trabalho de importantes coalizões de mulheres brasileiras. $^{9}$ Nesse cenário, algumas redes feministas estão incorporando a discussão sobre prostituição. Entretanto, tendem a fazê-lo em termos que se opõem a considerá-la como trabalho e/ou sua legalização. ${ }^{10}$ Assim, os ecos das "guerras do sexo", no que se refere à prostituição, parecem atingir setores do feminismo brasileiro, 20 anos depois, a partir do debate sobre o tráfico internacional de pessoas, fortemente impulsionado pelo peso de uma formulação legal supranacional, apoiada por agências multilaterais.

Um terceiro aspecto que caracteriza o debate se refere à escassa participação das organizações de prostitutas no processo. No Brasil, a história dessas organizações remete ao final da década de 1980. Atualmente, diversos grupos, com posições divergentes em relação à discussão sobre regulamentação/legalização da atividade ${ }^{11}$, estão integrados em

\footnotetext{
9 Ver página da Organização Sempre Viva (http://www.sof.org.br/).

${ }^{10}$ Posição das representantes de diversas organizações no Workshop "Prostituição Feminina, consolidado dos principais pontos debatidos", Secretaria Especial de Políticas Públicas para as Mulheres, 2008.

${ }^{11}$ Para um panorama de algumas dessas divergências ver Secretaria Especial de Políticas Públicas para as Mulheres (2008)
} 
redes, a Rede Nacional de Prostitutas ${ }^{12}$ e a Federação Nacional das Trabalhadoras do Sexo. De acordo com integrantes das duas redes, elas não foram chamadas para a consulta prévia à formulação da Política Nacional de Enfrentamento ao Tráfico. ${ }^{13}$ Nas (poucas) ocasiões em que representantes dessas organizações participaram dos grandes debates públicos, as intervenções provocaram tensões. ${ }^{14} \mathrm{O}$ motivo é que parte delas percebe a discussão sobre tráfico de pessoas como mais uma maneira, referendada pela opinião pública, de combater a prostituição. Nesse sentido, o fato de que algumas organizações de prostitutas se insiram no movimento de combate ao tráfico, estimuladas pelo apoio de agências transnacionais de financiamento, aparece como um ponto de tensão entre as trabalhadoras do sexo (Tavares, 2005).

Finalmente, outro aspecto particular da discussão sobre o tema no Brasil é que o movimento contra o tráfico de pessoas teve lugar no marco da vigência de diferentes definições legais. Este ponto, observado na apresentação deste dossiê e comentado em alguns artigos (Castilho, nv; Oliveira, nv), remete às diferenças entre as tipificações do crime de tráfico de pessoas no Protocolo de Palermo e no Código Penal Brasileiro. No primeiro instrumento legal, o crime é definido concedendo ênfase à coerção ou abuso de situação de vulnerabilidade em alguma fase do processo do deslocamento realizado para ser explorado em qualquer setor de atividade. No Código Penal, a definição não se baseia na articulação entre coerção e exploração, mas na intermediação ou

\footnotetext{
${ }^{12}$ De acordo com a informação apresentada no site do Grupo Davida, criado em 1992, a Rede Brasileira de Prostitutas se organizou a partir do I Encontro Nacional de Prostitutas, em 1987 (ver: http://www.davida.org.br/).

${ }^{13}$ Comunicação pessoal de representantes das duas redes em 2007.

${ }^{14}$ Cito como exemplo as reações suscitadas em torno das intervenções de integrantes de uma organização de prostitutas no Seminário Nacional de Enfrentamento ao Tráfico de Pessoas, realizado em Brasília, em outubro de 2007, organizado e apoiado pelo UN.GIFT, Ministério das Relações Exteriores, Unifem, OIT e IOM.
} 
Entre as "máfias" e a "ajuda"

facilitação de deslocamentos que têm como fim exclusivamente exercer a prostituição.

A presença das duas definições no debate público é perceptível ao olhar em matérias veiculadas na mídia brasileira, que aludem ao tráfico de pessoas, campanhas de organizações governamentais e decisões judiciais. Algumas reportagens noticiam o resgate de escravas no exterior, outras salientem apenas o fato de brasileiras estarem se prostituindo fora do país. As imagens das campanhas tendem a enfatizar a coerção, mostrando figuras femininas acorrentadas ou corações atrás de grades, mas a coerção não aparece como aspecto significativo em decisões judiciais (Oliveira, nv).

\section{Alternando entre definições}

As diferentes definições de tráfico de pessoas têm conseqüências na produção de conhecimento sobre o tema. Exames de decisões judiciárias proferidas por juízes federais e estaduais mostram que estão orientadas pelo artigo 231 do Código Penal (Castillo, nv; Oliveria, nv), e se referem a tráfico para exercer a prostituição, sem considerar a presença de coerção. Ao contrário, análises de casos atendidos por organizações não governamentais que seguem a definição do Protocolo de Palermo apresentam como pessoas em situação de tráfico homens e mulheres submetidos a cárcere privado, forçados a trabalhar sem pagamento em diferentes setores de atividade (Illes et alii, nv; ASBRAD, nv).

Alguns documentos, inclusive, misturam casos de tráfico definidos segundo os dois instrumentos legais. O Dossiê de Casos Emblemáticos de Tráfico de Pessoas, elaborado pelo Escritório de Prevenção e Enfrentamento ao Tráfico de Seres Humanos de São Paulo, oferece um exemplo. ${ }^{15} \mathrm{O}$ dossiê apresenta 12 casos em processo de investigação. Alguns remetem ao Protocolo de

\footnotetext{
${ }^{15}$ Agradeço a Marina Pereira Pires de Oliveira ter me facilitado esse material.
} 
Palermo: viagem sob fraude de bolivianos e peruanos para trabalho forçado em confecções em São Paulo; tráfico para venda de órgãos; deslocamento de adolescente, mantido em cárcere privado e forçado a se prostituir. Esses casos são combinados com outros definidos como tráfico de pessoas pelo Código Penal e ainda com outros delitos. O dossiê sugere que a noção de tráfico é às vezes utilizada principalmente para intervir em espaços voltados para a prostituição.

Essas observações conduzem à conclusão de que, para compreender o tráfico de pessoas no Brasil, não é possível fundir resultados de pesquisas e documentos que definem a problemática de maneiras diferentes. Ao contrário, torna-se necessário examinar seriamente as conceitualizações presentes nesses documentos. Ao mesmo tempo, é importante levar em conta que a definição de tráfico utilizada na realização das pesquisas tem fundamentais conseqüências nos resultados obtidos.

Essas implicações tornam-se evidentes, ao considerar a experiência de participação em duas pesquisas realizadas pela Secretaria Nacional de Justiça do Ministério de Justiça conjuntamente com outros organismos - UNODC e OIT -, com uma série de parcerias, sobre indícios de tráfico internacional entre pessoas deportadas e não admitidas que retornavam ao Brasil através do Aeroporto de Guarulhos (Secretaria Nacional de Justiça, 2006, 2007). Esses estudos tiveram resultados importantes, mostrando com clareza, já a partir de 2005, a terrível rejeição às brasileiras e suas detenções em péssimas condições em aeroportos europeus. No que se refere ao tráfico de pessoas, a história dessas pesquisas acompanhou nosso processo de construção de conhecimento sobre o tema $e$ apresentou alguns dilemas.

Os dois estudos estiveram norteados pelo Protocolo de Palermo. Contudo, a primeira pesquisa ${ }^{16}$ considerou indícios de tráfico em apenas algumas categorias de pessoas, mulheres $e$ travestis, para serem "exploradas sexualmente" na Europa. O

${ }^{16}$ Entre meados de março e abril de 2005. 
Entre as "máfias" e a "ajuda"

segundo estudo ${ }^{17}$ ampliou esse universo: incluiu homens $e$ considerou deslocamentos para trabalhar em qualquer atividade, também nos Estados Unidos. ${ }^{18}$ Uma das principais questões metodológicas, que surge da análise conjunta da realização dessas pesquisas, é a relevância da definição de tráfico utilizada. A segunda questão refere-se à importância de definir com nitidez a noção de exploração.

Olhando para trás, é possível perceber que o foco exclusivo na indústria do sexo reforçava as idéias de que o tráfico de pessoas está vinculado à prostituição e de que mulheres e travestis são as categorias de pessoas predominantemente expostas ao tráfico. Os pesquisadores foram orientados a realizar entrevistas qualitativas apenas com pessoas que, ao completar um questionário, afirmassem ter trabalhado na indústria do sexo. Essa estratégia metodológica teve o efeito de que perdêssemos a oportunidade de detectar indícios de tráfico de pessoas em outras atividades. Só por acaso, o diário de campo de um pesquisador registrou a experiência de uma mulher de 19 anos, de Goiás, que tinha trabalhado no serviço doméstico sem receber pagamento $e$ submetida a violência.

Na primeira pesquisa, em um universo de 175 pessoas, 13 entrevistadas afirmaram terem trabalhado na indústria do sexo. $\mathrm{Na}$ análise do material qualitativo foram adicionadas duas entrevistas realizadas em um piloto prévio à pesquisa. Das 15 pessoas, seis eram travestis. ${ }^{19}$ Seguindo o padrão de outros migrantes brasileiros, essas pessoas acionaram redes sociais para sair do país e se inserir em outro, não necessariamente grupos criminosos organizados, o que muitas pessoas entrevistadas

${ }^{17}$ Final de outubro e novembro de 2006.

${ }^{18}$ As duas pesquisas foram realizadas com diferentes metodologias, a primeira combinou abordagens quantitativa e qualitativa. Foi aplicado um questionário a 175 pessoas, das quais 15 foram entrevistadas em profundidade. Na segunda pesquisa, puramente qualitativa, foram entrevistadas 73 pessoas.

${ }^{19} \mathrm{Na}$ segunda pesquisa, seis pessoas - três mulheres e três travestis - afirmaram ter trabalhado na indústria do sexo. 
denominam de "máfias", mas todo tipo de redes, incluindo parentes, amigos, vizinhos, conhecidos. Através dessas redes obtiveram informações e ajuda para partir, para chegar, para obter abrigo $e$ integrar-se em algum nicho do mercado de trabalho. Olhando para esse universo a partir do Código Penal, essas quinze pessoas poderiam ser consideradas traficadas, pois em todos os casos houve algum tipo de intermediação para exercer a prostituição.

Vale observar que essas "ajudas", percebidas como facilitação, podem ser consideradas como vinculadas ao tráfico de pessoas de acordo com esse instrumento legal. Segundo Ela Wiecko V. de Castilho (2006), o termo "facilitar" abrange meios como fornecimento de dinheiro, papéis, passaporte, compra de roupas ou utensílios de viagem. De acordo com a autora, se uma brasileira que exerce a prostituição no exterior conta com a ajuda de alguém para a compra da passagem, ela não pratica crime, mas quem lhe empresta o dinheiro sabendo da finalidade, pratica o crime de tráfico. E o livre consentimento não exclui o crime.

$\mathrm{O}$ quadro se altera, porém, quando olhamos para o mesmo universo a partir do Protocolo de Palermo. Apenas três pessoas viajaram contraindo dívidas, uma mulher, convidada por uma amiga, e duas travestis, por cafetinas. Essas duas travestis foram as únicas pessoas que afirmaram terem sido enganadas ou sofrido coerção/violência em algum momento do processo migratório. Outras duas travestis adquiriram dívidas na "compra do ponto", isto é, do espaço na rua onde exerceriam a prostituição. Assim, cinco pessoas pareciam ter tido a obrigação de trabalhar para pagarem as dívidas.

Das dez pessoas restantes, duas mulheres deixaram algum percentual (entre 20 e 50\%) com o dono da boate onde trabalharam, e uma mulher trabalhou em um clube onde pagava diária por um quarto. Essas retenções deveriam ser consideradas "exploração da prostituição de outrem"? Finalmente, três pessoas trabalharam como dançarinas ou atrizes pornô. Seria este "outro tipo de exploração sexual"? 
Entre as "máfias" e a "ajuda"

\section{Ambigüidades}

As dúvidas estão associadas às expressões "exploração da prostituição de outrem" e "outras formas de exploração sexual", presentes no Protocolo de Palermo, mas não são definidas. Essa falta de clareza conceitual, que propicia interpretações diversificadas sobre o tráfico de pessoas, é atribuída a uma posição de aparente neutralidade no que se refere à prostituição. Esses termos e o "abuso de poder ou de uma posição de vulnerabilidade" são alvos de um acirrado debate (Munro 2008; Anderson e O'Connell Davidson, 2004).

No Protocolo de Palermo, a noção de exploração parece ter contornos mais nítidos quando se trata de atividades fora da prostituição, pois nesses casos é associada à idéia de trabalho forçado, escravatura, servidão. A exploração sexual é uma expressão sobre cujo conteúdo não há acordo no debate. As linhas abolicionistas consideram exploração sexual qualquer modalidade de prostituição, inclusive as que envolvem mulheres adultas que estabelecem contratos consensuais e trabalham de maneira autônoma (Barry, 1997). Já as abordagens que apóiam organizações de trabalhadoras do sexo não consideram a prostituição, em si, sinônimo de exploração (Jasmin, 1993; McClintock, 1993). Elas percebem a exploração como uma possibilidade aberta pelas características do mercado de trabalho, que se intensifica no âmbito do capitalismo globalizado (Kempadoo, 1998). ${ }^{20}$

A noção de abuso de poder ou de uma posição de vulnerabilidade, construída nesse debate, adquire relevância nas abordagens preocupadas com a visão de pessoas de regiões pobres do mundo, particularmente mulheres. O problema é que as percepções sobre quem está nessa situação contrapõem as

${ }^{20}$ Vanessa Munro (2008), ao analisar decisões judiciárias da Corte Européia de Direitos Humanos, mostra como as noções de trabalho forçado, servidão e escravatura são claramente esmiuçadas quando se trata de tráfico para serviço doméstico. Essa nitidez desaparece, porém, nos casos de tráfico sexual. 
mulheres de regiões ricas do mundo - concebidas como emancipadas $e$ independentes, com controle sobre seus rendimentos, corpo e sexualidade - com as "outras". Estas últimas são, axiomaticamente, consideradas pobres, ignorantes, precisando de conselhos e ajuda (Doezema, 2004; Kempadoo, 1998). Assim, as mulheres de regiões pobres que atravessam as fronteiras para oferecer serviços sexuais tendem a ser percebidas como vítimas de abuso de poder ou de uma posição de vulnerabilidade..$^{21}$

Porém, ao pensar na exploração na indústria do sexo com os critérios aplicados a outras atividades, essa noção remeteria ao trabalho forçado ou à servidão. No universo de pesquisa contemplado, nesse caminho, poucas pessoas poderiam apresentar indícios de tráfico.

\section{Gênero e setores de atividade}

$\mathrm{Na}$ realização da segunda pesquisa no aeroporto, o procedimento de alargar o universo de pessoas entrevistadas, incluindo homens, e de considerar os deslocamentos para trabalhar em qualquer atividade levantou questões adicionais. Vários dos homens tinham sido migrantes não documentados nos Estados Unidos, introduzidos por "coiotes" aos quais pagaram elevadas cifras. Assim, eles apareceram envolvidos no "contrabando" de migrantes que, embora também incluísse mulheres, nesse universo apareceu como predominantemente masculino.

\footnotetext{
${ }^{21}$ Essa observação vale também para a maneira como essa noção é utilizada no Brasil. Em um workshop, no qual participei em junho de 2008, um operador de direito que trabalha no Norte do Brasil explicou que considera que uma mulher da cidade possa tomar a decisão de deslocar-se para trabalhar na prostituição. Já mulheres pobres, com escassa escolaridade, morando em aldeias afastadas de um centro metropolitano, seriam vistas como vítimas de abuso de uma situação de vulnerabilidade.
} 
Entre as "máfias" e a "ajuda"

Nas análises do tráfico de pessoas considera-se que o tráfico de pessoas e o "contrabando" de migrantes constituem delitos diferentes, mas os casos reais podem apresentar elementos de ambos ou a mutação de um delito para outro (Naciones Unidas, 2007). O hábito de vincular o tráfico de pessoas com o trabalho na indústria do sexo e com mulheres e travestis, somado à pouca clareza conceitual da noção de exploração, em uma primeira leitura, teve como efeito que não observássemos essa mutação no material da segunda pesquisa. Contudo, ao considerar os trabalhos desempenhados pelos homens no exterior, era perceptível que, muitas vezes, eles eram submetidos a situações de trabalho que envolviam coerção, em condições extremamente duras e até cruéis. ${ }^{22}$

A maioria desempenhou atividades distantes da noção de trabalho digno, no sentido de lograr um rendimento justo, em um ambiente seguro, obtendo proteção social para si e seus familiares (OIT, 2005). Os relatos freqüentemente aludiam a pagamentos mais baixos que os oferecidos a pessoas em situação regular, ou a combinação entre baixos valores e a exigência de jornadas extenuantes, entre 12 e 16 horas diárias, praticamente sem descanso. Às vezes, mais de $50 \%$ dos rendimentos ficavam nas mãos de intermediadores, freqüentemente, brasileiros.

$\mathrm{Em}$ alguns casos, esses dois aspectos se combinam com condições de trabalho inseguras e nocivas à saúde em situações em que os migrantes, vulneráveis em função de sua situação irregular no exterior, eram submetidos a coerção. Um exemplo foi

\footnotetext{
${ }^{22} \mathrm{Na}$ Europa, esses entrevistados trabalharam em restaurantes, na construção, em indústrias e na agricultura, como estivadores ou, no comércio, como vendedores. As travestis trabalharam exclusivamente na indústria do sexo, seja como prostitutas ou atrizes pornô. As mulheres trabalharam na limpeza, em casas particulares, restaurantes, lanchonetes ou firmas, ocasionalmente no comércio, como vendedoras, ou repondo estoques em supermercado; e, nos EUA, na construção, realizando serviços mais "leves" que os masculinos, além de cuidarem idosos e crianças. Elas também trabalharam na indústria do sexo, como prostitutas ou dançarinas eróticas.
} 
oferecido pelo relato de um homem deportado dos Estados Unidos, que narrou uma experiência de trabalho com um patrão brasileiro definido como carrasco. Trabalhou na construção com um cimento mais corrosivo que no Brasil e sem a proteção adequada. Entrou de tênis no cimento, trabalhou o dia todo $e$ quando tirou o tênis no final do dia a pele do pé saiu agarrada na meia, ficou em carne viva. No dia seguinte ligou para o patrão $e$ falou que, por estar machucado não iria a trabalhar. O patrão concordou, mas à tarde ligou e falou "Amanhã você vai vir?" $e$ com tom irônico "Não sou eu que preciso de você". "Se você vir vai ter o seu trabalho, se você não vir..." perde o seu trabalho. Assim, voltou obrigado para o trabalho, com um pé que, durante vários dias, deixou a meia vermelha de sangue (Secretaria Nacional de Justiça, 2007).

A situação desse homem não remetia a situações análogas à escravidão, entendida como falta de liberdade, envolvendo aspectos como retenção de documentos, dificuldade de acesso ao local ou presença de guardas armados. No entanto, a coerção sofrida remetia à noção de trabalho forçado (Vasconcelos e Bolzon, nv). Aqui, a comparação com os relatos das entrevistadas que trabalharam na indústria do sexo é significativo.

Nas histórias das duas travestis, que afirmaram ter sofrido violência, falta de liberdade e ameaças exercidas com o fim de obter lucros a partir do seu trabalho na indústria do sexo, também remetem à idéia de trabalho forçado. Os relatos do conjunto de entrevistadas que trabalharam nesse setor de atividade, porém, indicam que tanto as que ofereceram serviços de forma autônoma como as que deixaram percentuais de seus lucros nos estabelecimentos o fizeram sem coação, nem engano, e muitas vezes em jornadas de trabalho inferiores a oito horas, em serviços percebidos como bem-remunerados. Nenhum desses relatos alude, em termos de dureza e pressão, às do homem que perdeu a pele no setor de construção. No entanto, a noção pouco clara de exploração sexual faz com que, em função da interpretação realizada, mesmo tendo como referência o Protocolo de Palermo 
Entre as "máfias" e a "ajuda"

elas também possam ser consideradas em situação de tráfico de pessoas.

$\mathrm{E}$ aqui, remetendo-me às pesquisas sobre migração de brasileiras inseridas na indústria do sexo, que realizei na Espanha, há um ponto sugestivo. Todas as minhas entrevistadas seriam consideradas traficadas de acordo com o Código Penal. Contudo, elas tinham uma percepção muito precisa do tráfico de pessoas, que diferia do Código e também de algumas leituras do Protocolo de Palermo (Piscitelli, 2007). Para essas mulheres, o tráfico de pessoas remetia invariavelmente à idéia de trabalho forçado, servidão por dívidas e escravidão.

\section{Crime e violações dos direitos humanos}

No início do século XXI, o combate ao tráfico de pessoas está envolvido na retórica da defesa dos direitos humanos das vítimas. A idéia é que as pessoas traficadas são sempre, e necessariamente, vítimas de um crime e vítimas de violação de direitos humanos (Munro, 2008). Nesse marco de idéias, um dos problemas enfrentados pela produção de conhecimento sobre tráfico de pessoas é que um grande número das pessoas integradas como vítimas do crime nas estatísticas governamentais sobre tráfico de pessoas, posteriormente, deixam de ser assim consideradas e são deportadas. ${ }^{23} \mathrm{E}$, ao contrário, freqüentemente pessoas caracterizadas como vítimas pelas tipificações legais não se reconhecem como tais.

O primeiro ponto está relacionado com leituras do tráfico de pessoas nas quais se entrelaça a percepção da problemática, ao mesmo tempo, como questão de crime organizado e de migração.

${ }^{23} \mathrm{O}$ Protocolo de Palermo deixa nas mãos de cada Estado parte adotar as medidas voltadas para atenção das vítimas e que permitam a elas permanecer em seu território nacional a título temporário ou permanente (Artigo 7). $\mathrm{O}$ quadro de impasses vinculados a esses aspectos é amplo e envolve questões relativas à prevenção (Friesendorf, 2007) e à atenção das vítimas (Munro, 2006; Piscitelli, 2006) 
Essa situação se delineia na Espanha, país no qual a adequação das leis nacionais às formulações legais supranacionais não necessariamente resultou na maior proteção dos sujeitos caracterizados como em situação de tráfico.

De acordo com autores que analisaram a evolução dessas leis, no Código Penal de $1995^{24}$, o exercício da prostituição envolvendo adultos sem mediar coação não era considerado delito. O proxenetismo era penalizado, mas só era considerado como tal o lucro obtido como resultado de coação, engano ou abuso de poder (Mestre, 2004). Na primeira metade da década de 2000, as leis foram reformuladas no âmbito das disposições legais da União Européia no que tange à repressão da migração não documentada e do tráfico internacional de pessoas. Na Espanha, o efeito foi a modificação conjunta das leis de prostituição e de Extranjeria, em 2003 (Cortes Generales, 2007).

Nas reformulações, a obtenção de lucros da prostituição, mesmo envolvendo maiores de idade que agem de maneira voluntária passou a ser delito e, de acordo com a Ley de Extranjería $^{25}$, se considera delito favorecer a imigração ilegal, com agravantes se o fim é a exploração sexual (Cantarero, 2007). A confluência entre essas duas disposições tem como efeito que a presença massiva de estrangeiras na indústria do sexo, muitas vezes não documentadas, seja lida de maneira quase automática como vinculada a atividades delitivas. Essa relação é freqüentemente traduzida na noção de tráfico internacional de pessoas. E essa tradução ofereceu elementos para não regulamentar a prostituição no país.

Um longo debate sobre o tema aberto por uma Comissão conjunta do Congresso e do Senado concluiu, em março de 2007, com a solicitação de não regulamentar a prostituição como trabalho, por considerar que se trata de exploração sexual, uma

\footnotetext{
${ }^{24}$ Artigo 188.1

${ }^{25}$ Artigo 318.
} 
Entre as "máfias" e a "ajuda"

violência contra as mulheres, vinculada ao tráfico de pessoas. ${ }^{26}$ Ao contrário, foi proposto um plano de luta contra a exploração sexual, incluindo medidas para diminuir a demanda. Paralelamente, foram implementados planos municipais de combate à prostituição de rua - alguns deles incentivados por comerciantes e pessoas que residem nos bairros onde existe esse tipo de prostituição ${ }^{27}$-, que multaram prostitutas e clientes $e$ foram acompanhados pelo controle da Polícia de Estrangeiros ${ }^{28}$, propiciando a deportação de migrantes não documentadas. Registros de organizações governamentais apontam para a violência às vezes sofrida por brasileiras nesses processos (ASBRAD, n.v).

Nesse quadro, os dados apresentados pela Guardia Civil Espanhola (Policia Judicial, 2005) em seus informes sobre Tráfico de Seres Humanos com fins de exploração sexual são significativos. No informe relativo a 2005, considera-se vítima toda pessoa que exerça a prostituição. Nesse ano, teriam sido detectadas em torno de 20.000 vítimas estrangeiras, das quais aproximadamente $25 \%$ seriam brasileiras. Mas, no total, apenas 140 mulheres se reconheceram como vítimas. São as "denunciantes", pessoas cujas denúncias contribuem para as investigações policiais. Apenas as que ofereçam informação

26 "Debate sobre la prostitución. El Congreso estudiará la prostitución. PSOE, PP e IU respaldarán que una comisión de la Cámara estudie cómo se debe abordar el sexo de pago". El País, 11/02/2006; "El Congreso aprueba por unanimidad crear una comisión sobre la regulación de la prostitución". El País, 15/02/2006; "La Comisión Congreso-Senado pide que no se regule la prostitución como trabajo". El País, 21/02/2007.

${ }^{27}$ Para uma análise desse tipo de alianças no combate à prostituição de rua, ver Bernstein (nv).

28 "Barcelona impone multas de hasta 3.000 euros a las prostitutas". El País, 11/02/2006; PLATAFORMA COMUNITÁRIA: TREBALL SEXUAL I CONVIVENNCIA: Comunicado de prensa: las entidades que conformamos la Plataforma Trabajo Sexual y Convivência denunciamos, 2006; "La mitad de las multas de la ordenanza cívica se imponen por pintadas y por beber en la calle". El País, 18/02/2006. 
significativa têm acesso ao estatuto $e$ à proteção a ser concedida às vítimas. Nesse cenário, a fusão entre prostituição e tráfico de seres humanos contribui na elaboração de elevadas cifras de estrangeiras vítimas de violação de direitos humanos. Ao mesmo tempo, o acesso a esses direitos é restrito e concedido exclusivamente a quem contribua para desmontar redes criminosas.

$\mathrm{Na}$ literatura sobre tráfico de pessoas, é recorrente a idéia de que pessoas traficadas não se auto-declaram vítimas por medo de represálias dos grupos criminosos organizados. Também é freqüente a percepção de que não se consideram vítimas porque estiveram numa situação de exploração por um longo período $e$ construíram uma dependência psicológica em relação aos exploradores. Outra possibilidade é que não reconheçam que a situação em que se encontram constitui um crime contra elas próprias (Almeida e Nederstigt, s/d).

Entre essas probabilidades, a idéia de não reconhecimento do crime é a mais próxima às das percepções de minhas entrevistadas na Espanha. Para examiná-la, considero o caso permeado pelo que entre elas foi considerado o mais extremo grau de violência. Ele foi narrado por uma mulher com características que a diferenciam da maioria das outras entrevistadas, a quem chamarei Verônica. ${ }^{29}$

Um desses traços é o estilo corporal, afinado com as preferências dos espanhóis que consomem sexo em nichos médios da prostituição - uma paulistana de 30 anos, esguia, mas de corpo bem torneado, com movimentos delicados e traços harmônicos, pele clara e cabelos escuros e sedosos. A outra característica que a distingue é seu nível de escolaridade. Diferentemente das outras mulheres que cursaram o ensino fundamental ou médio, Verônica iniciou o nível superior no Brasil. Fiz entrevistas com ela em diversos momentos. Quando a encontrei por última vez, em fevereiro de 2008, em Barcelona, ela morava na Espanha há três

${ }^{29}$ Para os resultados dessa pesquisa, ver Piscitelli 2007 e 2007a. 
Entre as "máfias" e a "ajuda"

anos. Nesse país, ofereceu serviços sexuais em clubes $e$ apartamentos e, finalmente, em uma casa de massagem.

Em São Paulo, Verônica se matriculou em uma faculdade, mas a abandonou quando começou a trabalhar na prostituição. No início, chegou a ganhar $\mathrm{R} \$ 8.000$ por mês. Quando o serviço começou a decair, procurou intensamente um contato na Espanha. Finalmente, após um ano, através de uma agência de viagens, chegou a um clube em Andaluzia. Viajou achando que receberia 100 euros por hora $e$, ao chegar, soube que deixaria a metade na casa. Devido à dinâmica "lenta" do trabalho, em um mês e meio ela ainda não tinha saldado a dívida de 2500 euros.

Verônica não gostou das condições de trabalho do clube na Andaluzia, considerando-as ruins, inseguras: "os clientes eram, na maioria, ciganos e marroquinos, que para nós são os piores clientes, porque põem faca no pescoço das garotas". Negociou o resto da dívida com um clube de Barcelona, onde a segurança era melhor $e$ os clientes espanhóis, e ocasionalmente turistas estrangeiros, "mais tranqüilos".

Nesse segundo clube, porém, se sentiu explorada. Verônica opera com a noção de exploração em termos financeiros:

me exploravam, pagava pela cama 450 euros ao mês e dividia o quarto com três garotas; não podia usar o celular para pedir comida, a gerente pedia e cobrava um absurdo, 20 euros por uma pizza pequena. No clube em Andaluzia a exploração era menor, saíamos para comprar nossa comida.

Verônica Saldou o resto da dívida em duas semanas. Depois de um tempo, já inserida em uma ampla rede de relações sociais, dividiu um apartamento com colegas. Ganhou "bem" durante um período, comprou uma casa em São Paulo e enviou dinheiro para a família regularmente (800 euros por mês). Fez amigos e amigas, espanhóis e brasileiros, teve namorados e tentou por diversos meios regularizar sua situação migratória. "Ajudou" uma irmã, 
enviando a passagem, a inserir-se também na indústria do sexo na Europa.

Nesse processo, o trabalho começou a se tornar mais escasso na Espanha: "muitas meninas, muita concorrência". Seu estilo corporal the possibilitaria trabalhar nos melhores apartamentos, sofisticados, seguros e caros. Entretanto, não tinha essa possibilidade, pois lhe exigiam "papéis". Começou a circular em apartamentos em cidades menores da Catalunha. Em um deles viveu uma situação de "violência terrível", que considera a pior experiência de sua vida:

Estava trabalhando... e um cliente tentou me matar... Agora está preso, já tinha denúncias por violação $e$ maus tratos... [Nesse dia] como demorava para sair [do quarto] minha colega bateu na porta, é um acordo que nós temos, e eu não respondi. Ela abriu a porta e me viu cheia de sangue... Ela tinha um spray paralisante e o usou, jogou nos olhos dele e saiu na rua correndo para pedir socorro. Ele foi para a delegacia e eu para o hospital... Agora trabalho em um lugar muito mais seguro, uma casa de massagens, ganho bem menos, mas é horário comercial e os clientes são gente comum...

Verônica associa a noção de violência a essa experiência. E percebe violência também no tráfico de pessoas, que associa à noção de violação de direitos humanos, através da idéia de escravidão. Segundo ela:

As escravas, essas sim são vítimas. Conheci uma, o pai a vendeu com 16 anos. Isso acontece muito com romenas e búlgaras. Na rua, uma delas começou a chorar, pedia por favor que a tirássemos dali. Essas querem fugir, voltar, mesmo que sejam deportadas. Não conheço nenhuma latina que tenha sido forçada. Mas procuram no lugar errado, porque buscam vítimas de tráfico entre as que vêm porque querem. Pegam porque algumas das garotas nos clubes estão ilegais, pegam por causa dos papéis e por isso 
Entre as "máfias" e a "ajuda"

são detidas e as deportam. Algumas acabaram de pagar a dívida e, no momento em que é possível começar a ganhar dinheiro para si, as deportam...

Cafetões violentos e máfias temíveis se entrelaçam na narrativa sobre a escravidão dessas vítimas. Mas Verônica considera que há distância entre suas próprias experiências e o tráfico de pessoas. Ela acha que o engano a que foi submetida foi mínimo, foi apenas falta de honestidade. Na sua leitura, a dívida faz parte do processo migratório daqueles que, como ela, não tinham recursos para sair do país. Mas, levando em conta o valor que precisou pagar, não considera que se trate de uma exploração financeira análoga à vinculada ao pagamento abusivo por alojamento e comida. Faz questão de sublinhar que no clube ao qual chegou, não cercearam seus movimentos, nem lhe retiraram o passaporte, só a "olhavam". Para demonstrar que não foi obrigada a ficar nesse lugar, me explica que uma das colegas que viajou com ela quis voltar ao Brasil sem ter pago a totalidade da dívida e o fez sem problemas. Ela atribui o trabalho sem condições de segurança, a exploração financeira e a brutal violência do cliente que tentou matá-la às condições de trabalho possíveis para uma migrante não documentada nesse setor de atividade.

A distinção entre crime, violência e violação de direitos humanos contribui para compreender as percepções de Verônica. Em um texto recente, Guita Grin Debert e Maria Filomena Gregori (prelo) refletem sobre a diferença entre os dois primeiros termos.

O crime implica a tipificação de abusos, a definição das circunstâncias envolvidas nos conflitos $e$ a resolução desses conflitos no plano jurídico. A violência é um termo aberto a disputas de significado, que implica o reconhecimento social mais amplo, não apenas legal, de que certos atos constituem abuso. Para entender esses sentidos é necessário prestar atenção aos processos interativos em que os envolvidos ocupam posições de poder desiguais. 
De outro lado, o que é tipificado como crime de tráfico de pessoas não necessariamente constitui uma violação dos direitos humanos. Segundo Vanessa Munro (2008), a existência de fraude, engano ou exploração justificam que se condene o tráfico de pessoas. Entretanto, fatores como a natureza do engano, o contexto da exploração e o grau de coerção são relevantes para estabelecer que houve violação de direitos humanos. Isso se torna evidente nas decisões da Corte Européia de Direitos Humanos, nas quais em que cada um desses aspectos é esmiuçado.

Nessas decisões, trabalho forçado, servidão e condições análogas à escravidão constituem violações desses direitos. Mas outras situações não necessariamente o fazem, embora sejam tipificadas como crime de tráfico de pessoas, principalmente quando envolvem prostituição. Em algumas circunstâncias, a idéia de violação de direitos humanos se sustenta apenas mediante uma leitura abolicionista da noção de exploração sexual.

É importante perceber que as decisões da Corte Européia, relativas à definição dos aspectos que constituem violações dos direitos humanos, mantêm relações com as percepções de minhas entrevistadas. A diferença consiste em que para essas mulheres, que mostram em suas noções os ecos de tantas campanhas contra o tráfico de pessoas, não há diferença entre tráfico de pessoas $e$ violações de direitos humanos. $\mathrm{Na}$ percepção delas, essas violações se materializam no cárcere, nos estupros, nas surras, às quais são submetidas as mulheres que elas consideram vítimas. Esse procedimento, utilizado para forçá-las a trabalhar na prostituição, está distante das experiências migratórias destas. Talvez, nesse cenário, a insistência presente em diversos âmbitos do debate público em fundir ambos os termos seja o principal fator que explica as concepções dessas migrantes.

\section{Conclusão}

Neste texto situei o debate sobre tráfico de pessoas na discussão internacional e brasileira, apontando para problemas 
Entre as "máfias" e a "ajuda"

que têm efeitos na produção de conhecimento. Não pretendi relativizar a gravidade do tráfico de pessoas, evidente nos textos deste dossiê, que mostram deslocamentos para a realização de trabalho escravo ou diversas modalidades de trabalho forçado. Minha intenção foi mapear impasses para pensar caminhos metodológicos que permitam analisar a problemática $e$ compreender as percepções das pessoas consideradas em situação de tráfico.

Mostrei, ainda, como a existência de diferentes definições de tráfico de pessoas e a falta de clareza conceitual dos termos que contribuem para delimitar a problemática, principalmente a noção de exploração, colocam sérios problemas para a produção de conhecimento também no Brasil. Nesse âmbito se produz a fusão entre crime e violação dos direitos humanos, às vezes utilizada instrumentalmente para reprimir a migração não documentada $e$ também para combater a prostituição.

Nesse cenário, as pessoas consideradas em situação de tráfico interpretam e incorporam noções de direito que, embora ancoradas em aspectos do debate público sobre o tema, não necessariamente coincidem com definições do crime de tráfico de pessoas. Ao mesmo tempo, observei que os casos tipificados como tráfico de pessoas nem sempre remetem a violações dos direitos humanos. Isso é valido para algumas leituras orientadas pelo Protocolo de Palermo e ainda mais para as que seguem o Código Penal brasileiro. Ao contrário, os procedimentos seguidos para reprimir o tráfico de pessoas podem violar esses direitos.

\section{Referências bibliográficas}

ADAMS, Niki (English Collective of Prostitutes). Anti-trafficking legislation: protection or deportation? Feminist Review, 73, 2003, pp.135-139.

Agustín, Laura María. Sex at the Margins, migration, labour markets and the rescue industry. New York, Zed Books, 2007.

AlmeIDA, Luciana Campello Ribeira de e NEDERSTIGT, Frans. Documento sobre critérios e fatores de identificação de supostas vítimas de tráfico 
de pessoas. Brasilia, Escritório das Nações Unidas contra Drogas e Crimes, Secretaria Nacional de Justiça, Ministério da Justiça, s/d.

ANDERSON, Bridget \& O'CONNEL DAVIDSON, Julia. Trafficking, a demand-led problem? A multy-country pilot study. Part 1 "Review of evidence and debates", 2004 (http://www.jagori.org/research_dst.htm).

AsSOCIAÇÃO BRASILEIRA DE DEFESA DA MULHER, DA INFÂNCIA E DA JUVENTUDE (ASBRAD); SECRETARIA NACIONAL DE JUSTIÇA/MINISTÉRIO DA JUSTIÇA; ESCRITÓRIO DAS NAÇÕES UNIDAS CONTRA DROGAS E CRIME. Metodologia de recepção e atendimento a mulheres e "trans" possíveis vítimas de tráfico de pessoas no universo de deportadas $e$ inadmitidas recebidas pelo Posto de Atendimento Humanizado aos(às) Migrantes, Brasília, 2008.

AUSSERER, Caroline. Controle em nome da proteção: Análise crítica dos discursos sobre o tráfico internacional de pessoas. Dissertação de mestrado, Instituto de Relações Internacionais, Pontifícia Universidade Católica do Rio de Janeiro, junho de 2007.

BARRY, Kathleen. Prostitution of sexuality: a cause for new international human rights. Journal of Loss and Trauma, 2:1, 1997, pp.27-48.

CANTARERO, Joan. Los amos de la prostitución en España. Barcelona, Ediciones BSA, 2007.

CASTILHO, Ela Wiecko de. A legislação penal brasileira sobre tráfico de pessoas e imigração ilegal/irregular frente aos Protocolos Adicionais à convenção de Palermo. Texto apresentado no I Seminário Luso Brasileiro sobre tráfico de pessoas e imigração ilegal, Cascais, 2006.

CHAME - Centro Humanitário de Apoio à Mulher. O que é que a Bahia tem. O outro lado do turismo em Salvador. Salvador, s/e, 1998.

CHAPKIS, Wendy. Live Sex Acts, Women performing erotic labour. Londres, Cassell, 1997.

Coletivo MulHer Vida. Sexo Turismo, o que a gente não faz para realizar um sonho?. Olinda, 1996 (Coordenação: Cecy Prestrello e Sandra Dias).

CoRnell, Drucilla. Introduction. In: Feminism and Pornography. New York, Oxford University Press, 2000, pp.1-19.

CORREAA, Mariza. Mulher e Familia: um debate sobre a literatura recente. BIB, o que se deve ler em ciências sociais no Brasil, n’s 15/19, São Paulo, Cortez, ANPOCS, 1986-1990, 1984. 
Entre as "máfias" e a "ajuda"

CORTES GenERALES - Comisión Mixta de los derechos de la Mujer y de la Igualdad de Oportunidades. Informe de la ponencia sobre la prostitución en nuestro país (154/9) aprobada en sesión de la ponencia del 13 de marzo de 2007.

DEBERT, Guita e GREGORY, Maria Filomena. Violência e Gênero. Novas propostas, velhos dilemas (prelo).

DOEZEMA, Jo. Now you see her, now you don't: Sex Workers at the UN Trafficking Protocol Negotiation. Social Legal Studies, 14, 2005, pp.61-88.

A crecer! La infantilización de la mujeres em los debates sobre "tráfico de mujeres". In: OSBORNE, Raquel. (ed.) Trajador@s del sexo. Derechos, migraciones y tráfico en el siglo XXI. Barcelona, Edicions Bellaterra, 2004.

Forced to Choose. Beyond the Voluntary v. Forced Prostitution Dichotomy. In: KEMPADOO, Kamala. Global Sex Workers, Rights, Resistance and Redefinition. New York/London, Routledge, 1998, pp.34-50.

FRIESENDORF, Cornelius. Pathologies of Security Governance: Efforts Against Human Trafficking in Europe. Security Dialogue 38, 2007, pp.379- 402.

Global Alliance Against Traffic In Women/Gattw. Collateral Damage. The Impact of Anti-Trafficking Measures on Human Rights Around the World. Bangkok, 2007 (http://www.gaatw.org).

Governo do Estado de São Paulo, SeCRETARIA DA Justiça E dA DeFesa DA CidADANIA, EsCRITÓRIO DE PREVENÇÃo E ENFRENTAMENTO AO TRáfICO DE PessoAs. Dossiê - Tráfico de Pessoas: Casos Emblemáticos. Mimeo, s/d.

GRUPO DAVIDA. Prostitutas, "traficadas" e pânicos morais: uma análise da produção de fatos em pesquisas sobre o "tráfico de seres humanos". Cadernos Pagu (25) - Mercado do Sexo -, Campinas-SP, Núcleo de Estudos de Gênero - Pagu/Unicamp, 2005, pp.153-185.

JASMIN. Prostitution is Work. Social Text, n 37, 1993, pp.33-37.

KEMPADOO, Kamala. From Moral Panic to Global Justice: Changing Perspectives on Trafficking. In: KEMPADOO, K., SANGHERA, Jyoti and PATTANAIK, Bandana. Trafficking and prostitution reconsidered, new 
perspectives on migration, sex work, and human rights. Boulder, Paradigm, 2005a, pp.vii-sxxiv.

Mudando o debate sobre o tráfico de mulheres. Cadernos Pagu (25) - Mercado do Sexo -, Campinas-SP, Núcleo de Estudos de Gênero - Pagu/Unicamp, 2005b, pp.55-79.

McClintock, Anne. Sex Workers and Sex Work, Introduction. Social Text, 37, 1993, pp.1-10.

MESTRE, Ruth. Las caras de la prostitución en el estado español. In: OSBORNE, Raquel. (ed.) Trabajador@as del sexo. Derechos migraciones y tráfico em el siglo XXI. Barcelona, Ediciones Bellaterra, 2004.

MiniSTÉRIO DA JUSTIÇA. Política Nacional de Enfrentamento ao tráfico de pessoas. Brasília, 2007.

MORAES, Maria Lygia Quartim. Marxismo e Feminismo no Brasil. Primeira versão, n 66, 1996.

MunRO, Vanessa. Of rights and Rhetoric: Discourses of Degradation and Exploitation in the Context of Sex Trafficking. Journal of Law and Society, vol. 35, n² 2 , June 2008, pp.240-264.

. Stopping Traffic? A comparative Study of Responses to the Trafficking in Women for Prostitution. British Journal of Criminology 46, 2006, pp.318-333.

MurRAY, Alison. Don't believe the Hype In: KEMPADOO, Kamala e DOEZEMA, Jo. Global Sex Workers, Rights, Resistance and Redefinition. New York, Routledge, 1998, pp.51-65.

NACIONES UNIDAS. Manual para la lucha contra la trata de personas. New York, 2007.

OliveirA, Marina Pereira Pires de. Análise da estratégia de agendamento do tema tráfico de pessoas na política pública brasileira, projeto de doutorado, Brasília, mimeo, 2008.

ORGANIZAÇÃO INTERNACIONAL DO TRABALHO. Uma aliança global contra o trabalho forçado. Relatório Global do Seguimento da Declaração da OIT sobre Princípios e Direitos Fundamentais no Trabalho. Brasília, 2005.

PISCITELLI, Adriana. Sujeição ou subversão? migrantes brasileiras na indústria do sexo na Espanha. Revista História e Perspectivas, n 35 , 
Entre as "máfias" e a "ajuda"

Universidade Federal de Uberlândia, Agosto-Dezembro de 2006 [2007] (http://www.historiaperspectivas.inhis.ufu.br/).

Corporalidades em confronto: gênero e nacionalidade no marco da indústria transnacional do sexo. Revista Brasileira de Ciências Sociais, vol. 22, n 64, junho de 2007ª pp.17-33.

Antropologia, direitos humanos e o debate sobre tráfico de pessoas com fins de exploração sexual. Anais da $25^{a}$ Reunião da Associação Brasileira de Antropologia, Goiânia, CD, 2006.

POLICIA JUDICIAL, GUARDA CIVIL. Informe criminológico, trata de seres humanos (con fines de explotación sexual). Madrid, 2005.

RAPPORT, Nigel e OVERING, Joanna. Social and cultural anthropology. The key concepts. Londres, Routledge, 2000.

SANGHERA, Jyoti. Unpacking the Trafficking Discourse. In: Kempadoo, Kamala, Sanghera, J. and Pattanaik, Bandana. Trafficking and prostitution reconsidered, new perspectives on migration, sex work, and human rights. Boulder, Paradigm, 2005, pp.3-25.

SARTI, Cynthia Andersen. O feminismo brasileiro desde os anos 1970: revisitando uma trajetória. Revista Estudos Feministas, vol. 12, n ${ }^{\circ} 2$, maio/agosto de 2004, p.35-50.

SECRETARIA ESPECIAL DE POlíticas PÚblicas PARA AS MULHERES. Workshop prostituição feminina, consolidado dos principais pontos debatidos. Brasília, mimeo, 2008.

SeCretaria NACIONAL DE JustiçA. Pesquisas em Tráfico de Pessoas, parte 3. Tráfico internacional de pessoas e tráfico de migrantes entre deportados (as) e não admitidos (as) que regressam ao Brasil via o aeroporto internacional de Guarulhos. Brasília, Secretaria Nacional de Justiça/OIT, 2007, (coord. técnica: Adriana Piscitelli).

. Pesquisas em tráfico de pessoas, parte 2. Relatório indícios de tráfico de pessoas no universo de deportadas e não admitidas que regressam ao Brasil via aeroporto de Guarulhos. Brasília, Secretaria Nacional de Justiça, 2006 (coord. técnica: Adriana Piscitelli).

SKACKAUSKAS, Andréia. Sexualidade, migração e relações de trabalho Uma análise do tráfico de mulheres sob a perspectiva das trabalhadoras sexuais, projeto apresentado ao doutorado em Ciências Sociais, Unicamp, mimeo, 2007. 
Adriana Piscitelli

SODIREITOS/GAATW REDLAC. Pesquisa tri-nacional sobre tráfico de mulheres do Brasil e da República Dominacana para o Suriname, uma intervenção em rede, Belém, 2008 (Redação do Relatório Brasil: Lúcia Isabel da Conceição Silva e Marcel Theodoor Hazeau).

TAVARES, Aline Godois de Castro. Relatório sobre o Colóquio Nacional: Os Profissionais do Sexo Contribuindo para o Enfrentamento da Exploração Infanto Juvenil, Goiânia, 13 a 15 de abril de 2005.

WEITZER, Ronald. The Social Construction of Sex Trafficking: Ideology and Institutionalization of a Moral Cruzade. Politics Society, vol. 35, $\mathrm{n}^{\circ} 3$, 2007, pp.447-475. 